\title{
AC 2009-1332: THE INNOVATION CHASE AND QUEST: A CASE IN EXPERIENTIAL LEARNING IN ENTREPRENEURIAL COMPETITIONS
}

\section{Donald Reimer, Lawrence Technological University}

Donald M. Reimer is currently a fulltime senior lecturer and Associate Director of The Lear Entrepreneurial Program in College of Engineering at Lawrence Tech. Mr. Reimer holds a Bachelor of Science degree in Industrial Management from Lawrence Technological University and a Master of Arts degree in Political Science from University of Detroit/Mercy. He is a Certified Management Consultant with over 35 years of experience in working with closely-held businesses. Mr. Reimer has served as an adjunct faculty member at Lawrence Technological University for over twenty-years. He has taught courses in entrepreneurship, management and corporate entrepreneurship and innovation for engineers. Mr. Reimer has operated his own consulting company - The Small Business Strategy Group for 23 years. He published numerous articles on small business, entrepreneurship and strategic thinking. Mr. Reimer conducted workshops and seminars for trade associations, chamber of commerce organizations and private companies. He has received several awards and recognition by local, state and federal agencies for his work in entrepreneurship and minority business development. Mr. Reimer served as member of the Minority Economic Development Committee of New Detroit. Mr. Reimer is member of the Small Business Advisory Council of the Detroit Regional Chamber of Commerce. Mr. Reimer is a member of Advisory Board of the Milwaukee Junction Small Business Assistance Center. He is also a member of the Applied Innovation Alliance. Mr. Reimer serves as a KEEN Fellow for The Kern Family Foundation and is a member of United States Association of Small Business and Entrepreneurship.

\section{Ahad Ali, Lawrence Technological University}

Ahad Ali is an Assistant Professor in Mechanical Engineering at the Lawrence Tech University. He earned B.S. in Mechanical Engineering from Bangladesh Institute of Technology, Khulna, Masters in Systems and Engineering Management from Nanyang Technological University, Singapore and $\mathrm{PhD}$ in Industrial Engineering from University of Wisconsin-Milwaukee. Dr. Ali was Assistant Professor in Industrial Engineering at the University of Puerto Rico - Mayaguez, Visiting Assistant Professor in Mechanical, Industrial and Manufacturing Engineering at the University of Toledo, and Lecturer in Mechanical Engineering at the Bangladesh Institute of Technology, Khulna. He has published journal and conference papers. Dr Ali has done research projects with Delphi Automotive System, GE Medical Systems, Harley-Davidson Motor Company, International Truck and Engine Corporation (ITEC), National/Panasonic Electronics, and Rockwell Automation. His research interests include manufacturing systems modeling, simulation and optimization, intelligent scheduling and planning, artificial intelligence, predictive maintenance, e-manufacturing, and lean manufacturing. He is member of IIE, INFORMS, SME and IEEE. 


\title{
The Innovation Chase and Quest - A Case in Experiential Learning in Entrepreneurial Competitions
}

\begin{abstract}
This paper describes experiences in participating in the competitions of the Chicago Entrepreneurial Quest and Milwaukee Innovation Chase. Both competitions consisted of five member teams competing in various assigned tasks. Seven other universities also competed in Chicago. The team focus was on creating a device that would be a reasonable replacement for cash, credit cards, or any other traditional method of payment in today's society. This experience provided each of our team members an opportunity to participate in a real entrepreneurial experience. The experience included a business opportunity assessment, an elevator pitch and other interactive exercises. The second competition in Milwaukee focused on marketing and brainstorming new and innovative ideas surrounding the sponsors' Chevrolet, OMAC, and OnStar products and presenting them in front of a committee similar to that in the real world. This event stared with a single clue. The teams of undergraduate students from eight universities followed a path of quick decisions, innovation and money to compete for cash prizes. Milwaukee Innovation Chase was carried on streaming video. The event consisted of a series of exercises including a sales pitch, a product enhancement presentation, marketing strategy, product accessory design and servicing a vehicle at a dealership. Each team was given a new Chevy product to drive during the competition. It was their job to learn as much about this vehicle as possible and communicate that knowledge to the judges. This event was unique in many ways. The knowledge and real world experience gained from the competitions was a significant learning experience. Our students learned many lessons about themselves and about working in a team environment. Through their experiences each team member gained a better understanding of their strengths and non-strengths. The combined events provided real life experiences in competitiveness and the entrepreneurial journey. It's also worth mentioning that this activity has given the students some valuable life lessons that could not have been learned over several semesters in the classroom. From team participant feedback, undergraduate students indicated that they had leaned so much about the entrepreneurial experience. Students displayed a remarkable combination of strengths in our team. Overall, team experience with both of the 2008 Entrepreneurial Quest and Innovation Chase competitions were very positive experiences that incorporated LTU's focus on theory and practice.
\end{abstract}

\section{Introduction}

This paper focuses on the unique learning experiences of five undergraduate students from Lawrence Technological University in Southfield, Michigan. The lessons learned at the Illinois Institute of Technology and the Milwaukee School of Engineering provided an innovative "hands-on" learning experience in Chicago and Milwaukee on April 11-12, 2008.

This article presents an overview of individual and team experiences in a highly competitive entrepreneurial environment. Eight schools participated in both events. Each school sent one five-student-team to participate in the event. The teams were cross-disciplinary and represented broad backgrounds and experiences. The Lawrence Tech team was represented by three 
engineering and two management students. Our team of two men and three women were members of the Lawrence Tech Chapter of the Collegiate Entrepreneurs' Organization (CEO). In addition to students, each team was accompanied by a faculty advisor who was not directly involved in the event.

The Innovation Quest, held at the Illinois Institute of Technology, and the Innovation Chase held at the Milwaukee School of Engineering are annual events. The sponsors included: The Coleman Foundation, The Kern Entrepreneurship Education Network, and The Entrepreneurship Program of the Stuart School of Business of the Illinois Institute of Technology, Chevrolet Division of General Motors, OnStar and Milwaukee School of Engineering.

\section{Team Selection}

The students selected to participate in these competitive events were members of the Lawrence Tech Chapter of the Collegiate Entrepreneurs' Organization and had participated in other extracurricular activities as well. The student team was cross disciplinary and represented the Colleges of Engineering, Architecture, Business and Arts and Sciences. Our entrepreneurial program is founded on fostering the "entrepreneurial mindset with a global view [1]." Lawrence Tech students have a rich history of participating in competitive events. These events nurture creativity, innovation and leadership skills. All of these skills are an integral part of our entrepreneurial and leadership curriculum. Our students participate in E-Teams, Senior Projects, Invention 2 Venture Seminars, Alumni Entrepreneurial Lecture Series, Element One Vehicle Project, Formula One Competition and Solar Decathlon.

\section{Event One - Chicago Entrepreneurial Quest}

The Innovation Quest was held on Friday, April 11, 2008 at the downtown campus of the Illinois Institute of Technology. All of the activities associated with the Quest were held in the downtown Chicago area.

The event began with an orientation at 8:30 AM on the day of the event. Each team and their faculty advisor participated in the orientation. Instruction kits were distributed to each team leader. Four team members performed a variety of assigned tasks in the field. Details of the tasks performed are described later in this paper. A team leader was selected by team members and provided leadership for their team in the field. In addition, team members also selected a base commander. This person communicated with the field and prepared a business plan document as well as performed research using the internet. Cell phones were used to communicate with teams. All event activities were timed and points were awarded for completing the assigned tasks within the allocated time. Student teams worked on each assigned task. The time constrains were challenging as each team had to complete their respective tasks on time or they were penalized for not doing so. Therefore, team work was critical and effective time management a must. Teams were judged based on their effective utilization of time.

The event began with one clue that was given at the orientation on Friday morning. Each team began their journey that involved quick business decisions, innovation and money to compete for 
cash prizes. There were a total of three cash prizes: first place team received $\$ 2,000$, second place $\$ 1,000$ and third place $\$ 500$.

The Quest Team from each school began its journey in downtown Chicago. Several Chicago area businesses and organizations hosted tasks to test the participants' entrepreneurial skills. Clues lead the team members from one location to another until they arrived at the site of the Quest's four main tasks. The Quest main tasks were the following: Presentation of an Elevator Pitch, Development of a Rapid Prototype, Venture Capital Interview, and the development of a written Business Opportunity Report.

All Quest activities were recorded and available online. The team must complete all of their tasks by 3:00 PM. The closing ceremony was held at 4:00 PM. Cash prizes were presented to the winning team at the conclusion of the Quest.

\section{Participating Schools}

The following eight schools participated in the Chicago Entrepreneurial Quest: St Louis University, Lawrence Technological University, Milwaukee School of Engineering, Illinois Institute of Technology, Kettering University, Bradley University, University of Detroit Mercy and University of Illinois-Chicago. Each school is a member of the Kern Entrepreneurial Education Network (KEEN) and is funded by the Kern Family Foundation. The mission of KEEN is "to graduate engineers with an entrepreneurial mindset who will contribute to business success and in so doing transform the U.S. workforce [2]."

\section{Activity Description}

The activities of the Chicago Innovation Quest can be described as both engaging and stimulating. The activities were designed by the event planning committee. Each team was given similar tasks in the field (downtown Chicago) and the base. The field events consisted of a preplanned journey through downtown Chicago whereby each team was faced with the challenge of finding various landmarks and locations. The entire journey was timed and each team was judged based on completing the tasks on time.

\section{Activity Experience}

Prior to leaving for downtown Chicago, each team was given similar instructions. However, each team began the competition at different times. The activities in Innovation Quest engaged the students in the challenges of uncertainty. The following describes our experience:

\section{Downtown Chicago}

This experience began with one clue given at the orientation meeting along with the instructions. Each team was provided with transportation and lunch vouchers for their journey in downtown Chicago. For those students who knew nothing about Chicago and its transportation system and landmarks, this was a real challenge. Getting around Chicago and finding clues to the next destination was an integral part of the learning experience. Often the team base commander 
would communicate with the field team to assist when possible. It was important to keep the team moving to complete the journey on time.

\section{Rapid Prototype}

Each team was given a limited selection of raw material - paper, plastic, paper clips, duct tape, cardboard and the like. The teams that arrived late from their field tasks in downtown Chicago were unable to obtain a good selection of raw materials to build their prototype. Not having an adequate selection of raw materials made it difficult to compete in this portion of the event. This exercise was designed to stimulate creativity and innovation. The design of a product and the creation of a prototype challenged the students. The judges evaluated the prototype based on originality, creativity and functionality. The scarcity of raw material is an example of a challenge faced by an entrepreneur.

\section{Business/Marketing Plan and Opportunity}

All teams were required to develop a Business Plan/Marketing Plan document. Our team focused on creating a device that would be reasonable replacement for cash, credit cards or any other method of payment. An eye scanning device was created to secure transactions. The commander at the base station researched the project on line and prepared the document for presentation. In addition, the base commander received feedback from other team members in the field. This task was difficult and at times overwhelming considering the time constraints. The document was completed on time and submitted to the judges. The Business Plan was reviewed and evaluated by its content, organization, validation (research) and potential business opportunity.

\section{Elevator Pitch}

This event provided an opportunity for one of our team members to sell an idea by organizing and presenting the idea to others. In most instances the Elevator Pitch is presented in a conversational style. The challenge is to convince someone to share your ideas and invest in the opportunity you are presenting. One student from the team presented an Elevator Pitch to a panel of judges. The presentations were judged based on the content, style, delivery and communication skills.

\section{Venture Capital Interview}

Each team had an opportunity to meet and interview a leading Chicago area venture capital firm. This experience provided team members with an opportunity to engage professionals who financed business opportunities. Since each team had to create a business plan for their business idea, securing financing was an integral part of the process. The team discussed marketing, equity, profitability, cash flow, debt service, return on investment and their business model. This was an excellent example of real world experience faced by entrepreneurs. 


\section{Chicago - Student Learning Experiences}

The Chicago event was designed to provide experiential learning for the student. The following feedback provides some insight into the lessons learned:

\section{Team Leader}

The team leader learned how important it was to maintain a positive attitude. She had not spent any time in downtown Chicago; therefore, she lacked knowledge of her surroundings. A valuable lesson from this experience was recognizing the importance of being aware of and understanding the environment in which the competition was held. Although students had instructions and resources, much of what happened in Chicago was based on the leader's own initiative, creativity and ability to meet the challenges of the assigned tasks. Life has its own challenges and a successful entrepreneur must learn to compensate for what happens. The team leader learned valuable communication and leadership skills. This experience also provided lessons of the challenge of uncertainty.

\section{Team Base Commander}

The base commander supported the team and provided key resources for them to make decisions. The team relied on her ability to find answers when they could not. She learned some valuable lessons about team work. It was not easy to come together in a strange environment. Each team member brought their own experience and knowledge. They also learned how important communication was as a key success factor. Not knowing where the team was at any point became a real challenge. The most important lesson learned was what she learned their mission. She learned about group dynamics and interaction.

\section{Team Member}

This team member was a senior in Mechanical Engineering and brought his background and experiences to the group. He shared the vision and mission. He had been involved in other projects at the University. This experience capitalized on the team member's previous leadership experience. Since this team member entered the group late, he did not know the others in the group prior to the Chicago experience. Most of his knowledge of the other team members was the result of the four plus hours spent traveling to Chicago. The team experience taught him about his own expectations. He found the Innovation Quest enhanced his oral communication skills. Past experiences served as the foundation for building leadership and management knowhow.

\section{Team Member}

This Team Member was a junior in the Mechanical Engineering program. He found that his experience in the engineering curriculum was of great value. Engineering is all about solving problems. The team was faced with numerous problems and opportunities. The team members worked to complete the assigned tasks in a timely manner. The pressure of the time constraints was difficult. However, he felt this was an important part of the learning experience. The 
challenge of solving a problem under pressure is often the case in the business world. $\mathrm{He}$ believes the ability to work under pressure is very important. Our team was under pressure and we had to get the job done on time. He felt the experience assisted him with improving his communication and presentation skills.

\section{Overall Student Learning Experience}

Each student had their individual learning experiences. In summarizing their collective learning experiences, the following would best describe the lessons learned by students participating in this unique experiential learning exercise: Team building skills, self confidence, oral and written communication, group interaction, and creative problem solving and risk assessment. The event created an understanding of group dynamics and the power of working together to solve problems and overcoming obstacles to achieve the mission of the group. One of the most valuable lessons learned by team members was how to manage uncertainty. The entrepreneurial journey is often an uncertain path. Each team members brought innovative ideas to address solving the problems the group faced with the assigned tasks.

\section{Event Two - Milwaukee Innovation Chase}

The Milwaukee Innovation Chase (MIC) was held on Saturday, April 12, 2008 at the Milwaukee School of Engineering in Milwaukee, Wisconsin. Upon completion of the Chicago Entrepreneurial Quest, our team participated in the Milwaukee event. Although there were similarities, both events were different in many ways. Both events were entrepreneurial in spirit and driven by intense competition. The competitive spirit was evident in every team. Leadership skills and management style were apparent as each team performed their assigned tasks.

The event brought together private sector sponsors including Chevrolet Division of General Motors, OnStar and a local Chevrolet dealership. The Milwaukee School of Engineering was the key sponsor and provided planning, coordination and operational support for the event. The involvement and commitment of the private sector enhanced the learning experiences of all of the participants.

\section{Participating Schools}

The following schools participated in the Milwaukee Innovation Chase: Bradley University, Illinois Institute of Technology, Milwaukee School of Engineering, University of Illinois Chicago, Lawrence Technological University, and Milwaukee School of Arts \& Design, Marquette University and Valparaiso University. Each school was represented by a six student undergraduate team and a faculty mentor.

\section{Activity Description}

Upon arrival at the Milwaukee School of Engineering, each team was presented with a new Chevrolet product. The faculty mentor was assigned the vehicle and the team was given all of the specifications and marketing material for the assigned vehicle. Each vehicle was equipped with 
an OnStar program. The assigned vehicle was an integral part of the MIC event. Each team was responsible for learning as much as possible about the vehicle and its features. The OnStar program was used as a tool to navigate the various assigned destinations in the Milwaukee areas.

The MIC event also included a team leader and a base commander. The leader worked in the field with other team members, and the base commander remained in the base location working online and communicating with the field team as they executed their respective assignments.

The MIC included activities that provided each student with an opportunity to have an entrepreneurial "hands-on" learning experience. Each team participated in the following events: Opening Event, Opportunity Assessment, Elevator Pitch, Rapid Prototyping, Ethnographic Study, Marketing Interview, Design Thinking and Small Tasks.

\section{Activity Experience}

\section{Chevrolet Dealership - Oil Change and Tire Rotation}

This experience was designed as an exercise in leadership, team interaction and communication. Each team was assisted by a dealership service technician. It was apparent that some of our team members had experience in working on vehicles. Others had no previous experience with this task. Each team was timed in the process of changing the oil and rotating the tires of the vehicle. The team was judged on how well they worked together to complete the assigned tasks. The time to complete the task was also used to evaluate Team performance

\section{Chevrolet Dealership - Assessment of Vehicle and Design Thinking}

The team was asked to assess the vehicle in terms of their age group and student population. Each student had to develop a feature or option that could be added to the vehicle to appeal to their market segment. The interview was conducted by marketing specialists from Chevrolet Division of General Motors and the dealership. This task was recorded using streaming video for all of the participants to view. The team was evaluated based on the presentation skills, content, originality, imagination and practicality.

\section{OnStar - Interview}

Each team member was required to present a marketing strategy to reach the college market with the OnStar service. The team met for one hour prior to their presentation. They had an understanding of OnStar and its current business model. Based on the information provided by OnStar earlier that day, they were successful in presenting the best approach to reach the target market. Representatives of the OnStar marketing department asked questions and interacted with the team members. The team was evaluated based on their presentation content, product knowledge, communication and sales skills. 


\section{Vehicle Sales Pitch}

The team was required to deliver a sales presentation to representatives of the Chevrolet Division of General Motors. The presentation was given by one team member who was most familiar with the Chevrolet Impala. This is the vehicle the team was given to use during the event. Material and brochures were given to the team to provide product knowledge. Prior to the sales presentation, the team spent time learning as much as possible about the specific features of the vehicle. The representatives of Chevrolet focused on asking question to determine the depth and understanding of the product and its features. They judged the presentation based on real world sales techniques used at Chevrolet dealerships.

This experience required strong oral communication skills and exceptional product knowledge. The interaction with the customer, the Chevrolet representative, provided an experiential learning exercise that was very effective. The feedback received from the customer was very favorable.

\section{Milwaukee - Student Learning Experiences}

This paper focuses on the individual learning experiences of five students who participated in MSOE Innovation Chase in Milwaukee. Prior to this event, our students had no experiences in participating in competitive events of this type. The uniqueness of this event was the opportunity to bring students together from other schools to participate in a competitive entrepreneurial journey. The following are examples of the individual student learning experiences:

\section{Team Member}

The MSOE Innovation Chase provided him with an opportunity to use his background and experience. My team members came together with a common vision and mission - winning. The greatest challenge was keeping the goal in mind. Each team member brought their experience and knowledge. The event was very competitive and each university wanted to win. Each exercise was all about team work and leadership. This team member learned a lot about himself and his commitment to staying focused. He also learned a very important lesson about the dynamics of the team. When working in a team, it is highly advantageous to understand and know your team members as much as possible.

\section{Team Member}

As our team began its participation in the MSOE event, this team member realized the Milwaukee Innovation Chase was different than Chicago. The relationship of the leader and base commander were the same as in Chicago. Since the event was spread out over many miles, the use of a new Chevrolet equipped with OnStar provided a variety of interesting interactive experiences. As a team member, the MSOE taught her the importance of team members working together to achieve the goal. MSOE provided real time communication during the entire event. All of the teams knew exactly where they were in the standings. The use of technology was excellent and was an integral part of all activities. This team member learned how to deal with 
stress and uncertainty. The most important lesson for this team member was keeping a positive attitude and learning how to listen to others.

\section{Team Member}

This team member is a very competitive person. He is a junior in the College of Engineering with an extensive background in working on teams. The Milwaukee Innovation Chase provided a great opportunity to be part of a unique experience. .He joined the team with a commitment to win! The Milwaukee Chase gave him an opportunity to improve his communication skills. The Team presented to a group of judges from Chevrolet and OnStar. This was difficult for him. He did it and felt great! This experience improved his confidence and enhanced his communications skills. As a result of his presentations to the judges, he reduced his fear of public speaking.

\section{Team Member}

He is a senior in Mechanical Engineering and had extensive experience in working on teams prior to this event. He was ready for the event and felt confident he could bring much to the team and its mission. The team brought together different disciplines - management, engineering, and architecture. He learned how important communication and leadership skills are in this type of activity. He also learned about the importance of understanding and sharing the vision and mission. Since we had just completed the experience in Chicago, the team members had an opportunity to work together as a unit. This was helpful in the Milwaukee event. This team member improved his presentation skills and the effectiveness of his oral communication in the elevator pitch.

\section{Overall Student Learning Experience}

The students had learned from the Chicago experience. They had similar learning experiences at the MSOE Milwaukee event. However, the events were very different in many respects. The following best describe the lessons learned by the team members at the MSOE event: product design, marketing and marketing strategy, group presentation skills, organizational behavior and group dynamics, selling techniques, written and oral communications skills and leadership. Since MSOE had private sector sponsors, this provided insight into the automotive industry and the distribution network - the dealership as an independent family owned and operated business.

\section{Faculty Mentor - Learning Experiences}

The role of the faculty mentor was to listen, support and guide the team. The mentor was not directly involved in the various tasks and activities of the team. At times, it became difficult not to become directly involved in the decision making process. Solving problems and making decisions are an integral part of experiential learning. Each student participant had to learn the importance of working with his/her team members.

The faculty mentor listened to each team member as they faced the challenges of completing the various activities in a timely manner. Words of frustration, joy and satisfaction were shared with the faculty mentor as well as others on the team. As is often in a team environment, the 
leadership skills surfaced. On the other hand, team members found some of their teammates were not dependable.

In some instances the faculty mentor would listen, console and offer encouragement to the team as a whole as well as to individual members of the team. Both events provided an opportunity to learn more about working within a team environment.

\section{Preparation Guidelines for Future Competitions}

In order to maximize the performance of the team the following action steps should be taken prior to the event:

- Develop and implement a process to identify and select the ideal students to participate in this competitive event.

- Select team members based on their individual strengths and skills with special attention give to their ability to work effectively in a team environment.

- Consider a campus wide contest to identity and select a cross-disciplinary group with various skills including, written and oral communication, creativity, innovation, problem solving, and leadership.

- Conduct team building exercises with an emphasis on group dynamics, oral and written communication and product design.

- Identify possible team leaders who can provide the leadership skills necessary to achieve the mission.

- Assess the connectively of the team to determine how well the individual team members get along.

\section{Lawrence Tech Entrepreneurial Program}

Lawrence Tech is a private university founded in 1932 and is located in the Detroit region. Its entrepreneurial program was created in 2001 with a gift from the Lear Corporation in Southfield. The gift established the Lear Entrepreneurial Program within the College of Engineering. The program offers a Certificate of Entrepreneurship which is available by completing three one credit hour courses. In addition to the Lear Entrepreneurial Program, Lawrence Tech offers other entrepreneurial activities to foster the entrepreneurial mindset among its students. These activities included the following: Collegiate Entrepreneurs' Organization, The LEGENDS Alumni Entrepreneurial Organization, Entrepreneurial Lecture Series, Invention 2 Venture and access to outside competitive student entrepreneurial events. Lawrence Tech is a member of the Kern Entrepreneurial Education Network which is supported by The Kern Family Foundation.

\section{Experiential Learning and the Entrepreneurial Curriculum}

The entrepreneurial curriculum has continued to evolve in colleges of engineering across the United States. Judith Cone, Vice President of the Ewing Marion Kauffman Foundation stated that "we have barely scratched the surface in learning to teach entrepreneurship in fields other than business and engineering." Further, students must recognize opportunity, harness the resources to exploit that opportunity, exercise their creativity, create sustainable solutions, take the inherent risks, and participate in its rewards [3]. 
The Lifelong Learning for Entrepreneurship Education Professionals is an organization that is committed to enhancing the quality of entrepreneurial education and educators. In their 2009 promotional brochure on The Experiential Classroom, the organization stated that "we believe that an entrepreneurial education must be linked to the real world and that teaching must incorporate practice and hands-on learning [4]." Both the IIT and MSOE program are excellent examples of integrating hands-on learning into the curriculum.

Entrepreneurial curriculums now include experiential learning as an integral part of exposing the student to the entrepreneurial mindset. At Lawrence Tech, we have created an entrepreneurial curriculum that integrates experiential learning in our senior projects, community outreach, plant tours, E-Teams and laboratory environments. Our students participate in activities that provide experiential learning. We are now working on integrating entrepreneurial content into 30 existing courses. This includes the opportunity to link "theory and practice" through the integration of experiential learning into our engineering and arts and science curriculum.

Students who participate in experiential learning are better prepared to enter the world of the entrepreneur. The new entrepreneurial internship and coop program will provide an opportunity for our students to work directly with entrepreneurs in their companies. The LEGENDS of Lawrence Tech, our alumni entrepreneurial organization is participating in this program.

\section{Conclusions}

Prior to participating in the Chicago and Milwaukee competitions, students questioned the value of experiential learning. Both the IIT and MSOE events are great examples of powerful experiential learning experiences. By their testimonies, our students validated the importance of participating in competitive entrepreneurial events. The observations of the faculty mentors provided insight into this experiential learning approach. In Donald Kuratko speaks of the entrepreneurial mindset in the preface of his new book entitled, "Entrepreneurship, Theory, Practice and Process." He states that "entrepreneurship is a cohesive process of creativity, risk taking, and planning." He further states that "students today need courses and program that set forth a basic framework for understanding the process of entrepreneurship [5]." The process of understanding the entrepreneurial journey is brought to live through experiential events like the Innovation Quest and Chase. As entrepreneurial educators, we must create an experiential classroom that gives our students the opportunity to engage seasoned entrepreneurs.

In the reflection of the faculty mentor and advisor, he believes this type of learning must be integrated into building an entrepreneurial mindset. Students in engineering entrepreneurial programs must be involved in activities which take them outside the classroom. These activities provide an opportunity to learn from real world problem solving. Creativity, innovation, leadership, and group dynamics are important skills that are necessary for success as an entrepreneur or as a corporate entrepreneur.

It was recommended that faculty engagement is requirement for our students and we encourage them to participate in competitive events and team building exercises. The benefits of participating in these events far outweigh the benefits of not participating. 
As a result of the Lawrence Tech experience in the Innovation Chase and Quest, we are exploring the organization of a similar event. We believe the experience provided a solid foundation for the creation of an innovative and unique experiential learning experience.

\section{Entrepreneurial Educators - Taking Action}

Entrepreneurial educators who are committed to building the entrepreneurial mindset must foster a way of thinking, reasoning, and acting that is obsessed, holistic in approach, and balanced [6].

The following are specific action steps entrepreneurial educators can take to foster experiential learning within the academic environment:

- Encourage students and faculty to become involved in projects that foster hands-on learning.

- Create experiential activities to build the entrepreneurial mindset

- Engage entrepreneurial alumni to mentor students

- Become involve in programs to foster innovation among student E-team such as National Collegiate Inventors and Innovation Alliance (NCIIA)

- Establish events that will create competitive students events and foster entrepreneurial thinking.

- Identify students who can deliver elevator pitch presentations

- Create programs that will enhance oral and written communication.

- Identify outreach programs in the community who can benefit from student involvement in their activities

NCIIA recognizes the importance of innovation in the academic environments. Included in its mission statement is the following [7], "together, faculty, students, and practitioners across disciplines, providing students with hands-on experiential learning opportunities."

\section{References}

1. Lawrence Technological University, Southfield, Michigan, 2007 Strategic Plan.

2. Kern Family Foundation, Waukesha, WI, www.kffdn.org

3. Cone, J., Entrepreneurship, Ewing Marion Kauffman Foundation, Teaching Entrepreneurship in Colleges and Universities: How (and Why) a New Academic Field Is Being Built.

4. Oklahoma State University, The Experiential Classroom, Marketing Brochure, September 17-20, 2009

5. Kuratko, Donald K., Entrepreneurship - Theory, Process, Practice, South-Western, Eighth Edition.

6. Babson College and Harvard Business School, Definition of Entrepreneurship, enhanced by Stephen Spinellie, Jr. John H. Muller, Jr., Term Chair at Babson College.

7. National Collegiate Inventors and Innovators Alliance promotional brochure, www.nciia.org 